\title{
The Effect of Inorganic Nanoadditives on the Thermal, Mechanical and UV Radiation Barrier Properties of Polypropylene Fibres
}

\author{
Anna Ujhelyiová, Mária Slobodová, Jozef Ryba, Eberhard Borsig, Petronela Vencelová \\ Department of Fibres and Textile Chemistry, Institute of Polymer Materials, Faculty of Chemical and Food Technology, Slovak \\ University of Technology in Bratislava, Radlinského 9, 81237 Bratislava, Slovakia \\ Email: anna.ujhelyiova@stuba.sk
}

Received January 12, 2012; revised February 25, 2012; accepted March 1, 2012

\begin{abstract}
The objective of this study of modified polypropylene (PP) fibres using nanoadditives (nano- $\mathrm{CaCO}_{3}$ and Cloisite 30B) was to determine the influence of these additives on thermal and mechanical properties, but especially on the barrier properties of the nanocomposite fibres against UV radiation. The DSC data obtained from measurements of $\mathrm{PP} / \mathrm{CaCO}_{3}$ or PP/C30B nanocomposite fibres were used for determination of the constants $n$ and $K$ of the Avrami equation and in the estimation of other thermal properties of the fibres, such as their crystallization half-time $t_{1 / 2}$, rate of crystallization $\tau_{1 / 2}$, the necessary time for maximum crystallization $t_{\max }$ and free energy per unit area of surface in the lamella perpendicular to the axis of a high-molecular chain $\sigma_{e}$. The nano- $\mathrm{CaCO}_{3}$ or Closite 30B fillers (pre-treated separately in three different solvents: glycerine, acetone and water) did not influence the melting temperatures but caused an increase in PP crystallization temperatures in comparison with the pure PP fibres. The pre-treatments of nanoadditives resulted in increase of $n, K, \tau_{1 / 2}$ values and decrease of $t_{1 / 2}, t_{\max }$ as well as the values of free surface energies per unit area of the modified PP fibres. There was also observed a decrease in the mechanical properties, however, there was an increase of barrier properties against UV radiation of nanocomposite PP fibres in comparison with neat PP fibres, which was one of the main objectives of the study.
\end{abstract}

Keywords: Polypropylene (PP) Fibres; Nano- $\mathrm{CaCO}_{3}$; Cloisite 30B; Kinetics of PP Crystallization; Thermal; Mechanical and UV Radiation Barrier Properties

\section{Introduction}

One of the latest evolutionary ways of preparation of novel polymeric materials is the development of polymer/nanofiller materials with improved properties which allow their application in the manufacture of demanding equipment. The principle underlining the nanofiller effect on polymer matrix is based on the relatively high surface area of nanofiller particles and so possibility creating more intimate interactions with polymer chains. These can lead to crosslinks among polymer chains and throughout the physical polymer network. This effect of the nanofiller considerably influences the physical and mechanical properties of the polymer/nanofiller material. Therefore, incorporation of nanoadditives into a polymer matrix offers an attractive potential for diversification of conventional polymeric materials, such as iso-tactic polypropylene (PP) in various areas of technical application [1-5]. Nano-particles provide new application opportunities in plastic materials used in the areas of automotive, aerospace or electrical engineering industries. Thanks to the unique nano-size of primary filler particles, they offer some new properties such as transparency, improved abrasion resistance as well as unique colouristic effects. New generation of materials comprising nano-size particles with treated surfaces has resulted in a breakthrough in modification of thermosets and thermoplastics. A noteworthy advantage has already been realized from the use of nano-sized filler in that only a small addition of filler significantly increases impact strength as well as toughness of the polymer materials [6].

$\mathrm{PP}$ is an important commercial polymer with wide use in many areas such as packaging, automotive industry, fibres and textiles. Its wide use exhibits stems from an attractive combination of low cost, low weight, easy processibility, as well as desirable end-use properties [7]. The rapid growth of PP application in fibre form has lead to an increase in the production of non-woven materials by using spunbond and meltblown technologies. From the application standpoint there is still considerable interest in improving the properties of PP fibres. 
It may be expected that the higher surface area of nano-particles could enhance further the crystallization rate of semicrystalline polymers. The type and content of crystallinity plays an important role in the properties of oriented fibers produced for textiles. It has been found that the use of nanoadditives having the proper morphology and particle size, when compounded with polypropylene (PP) fibres induce different behaviour of the polypropylene during crystallization, as well as on the crystallization conditions [1-5].

During crystallization of polymers from melt, one observes in the first step the formation of nucleation entities and in the second step the growth of these entities. These steps influence the kinetics as well as level of crystallization. The influence of clay nano-particles on the intercalated PP-clay nanocomposites was investigated by Yuan et al. [8], Al-Mulla et al. [9], Philips and Manson [10] and Di Lorenzo and Silvestre [11]. They stated that the surfaces of the filler particles act as nucleation sites for semi crystalline polymers. Perrin-Sarazin et al. [12] indicated that the kinetics of crystallization (crystallization temperature and rate) and structure of PP is not only related to clay content, but also depends on PP-clay interactions. In the absence of coupling agent, the crystallization from the melt of PP containing clay platelets occurred faster and at higher temperature than that of neat PP. The type and amount of crystalline phase in PP has a significant effect on the end-use properties of nano-filled fibres, such as thermal, mechanical as well as barrier properties against UV radiation.

One possibility for protecting against harmful ultraviolet radiation (UVR), mainly on the skin, is to wear suitable clothing made of safety textile materials $[13,14]$. The shielding properties of textile materials depend on their chemical and physical characteristics [15]. Nanoadditives, such as $\mathrm{TiO}_{2}, \mathrm{CaCO}_{3}$, clay or $\mathrm{ZnO}$ are intended to improve barrier properties as well as mechanical or thermoplastics properties in different plastic materials, like coatings, packaging, etc. [16]. Thus it seemed reasonable to modify the PP fibres by $\mathrm{CaCO}_{3}$. These fillers are commonly used in large quantities in the processing of PP for various applications.

The larger surface area and dimensional aspect ratio of inorganic nanoadditives provides for more numerous nucleating sites for PP crystallization. Nanoclay Cloisite 30B-C30B consists of plate-shaped filler particles with high aspect ratio which produce more numerous nucleating sites for PP crystallization than do $\mathrm{CaCO}_{3}$ nanoparticles, which have spherical particles and lower aspect ratio is [17]. The chemically modified $\mathrm{CaCO}_{3}$ caused significant changes in the thermal behaviour mainly during PP crystallization. It affects the total degree of PP crystallinity, the crystallization rate and crystallization temperature. The mechanical properties of PP modified with nano- $\mathrm{CaCO}_{3}$ have been increased, too [18]. So, the thermal and mechanical properties of conventional polymers can be significantly influenced using fillers that act as artificial nucleating agents [3]. However, inorganic nano-particles very easily agglomerate because of their large specific surface area and high surface energy and they show poor dispersability in nonpolar polymers like $\mathrm{PP}$, resulting in poor mechanical properties [18].

On the basis of previously published work, we have chosen nanoadditives Cloisite $30 \mathrm{~B}$ and $\mathrm{CaCO}_{3}$ for modification of PP fibres and have examined their thermal, mechanical as well as barrier properties against UV radiation $[19,20]$. The advantage of both fillers, $\mathrm{CaCO}_{3}$ and $\mathrm{C} 30 \mathrm{~B}$, is that the products are dyeable, an important requirement of textile producers. Mechanical property measurements such as tenacity, modulus and elongation were carried out and thermal properties of the modified PP fibres were evaluated by DSC analysis. The barrier properties against UV radiation were determined by a spectrophotometric method, which provide a basis for evaluation of the shielding effect of fibres containing both nanoadditives: Cloisite $30 \mathrm{~B}$ and $\mathrm{CaCO}_{3}$.

\section{Experimental}

\subsection{Materials}

Polypropylene TG 920 (PP) with the melt flow index MFI $=10.5 \mathrm{~g} / 10 \mathrm{~min}$, supplied by Slovnaft Corporation was used in the preparation of unmodified and modified PP fibres. Two types of nanoadditives (NA) with various aspect ratios and nanoparticle size were used. Nano$\mathrm{CaCO}_{3}$ filler $\left(\mathrm{nCaCO}_{3}\right)$ with the commercial name Socal U3 (Corporation Solvay) has mean particle diameter $=20$ $\mathrm{nm}$, free flowing density $=170 \mathrm{~g} / \mathrm{l}$ and specific surface $=$ $70 \mathrm{~m}^{2} / \mathrm{g}$. Cloisite 30B (C30B, from the corporation Southern Clay Products), Inc. is a natural montmorillonite modified with a quaternary ammonium salt. The chemicals used for nanofiller treatment were glycerine with the density of $1260 \mathrm{~kg} / \mathrm{m}^{3}$ and acetone with the density of $790 \mathrm{~kg} / \mathrm{m}^{3}$. Both liquids were analytically pure commercial products (fa Lachema, Czech Republic). The information of the used materials is available according to the Technical Data Sheet and Product Bulletin of the source corporations.

\subsubsection{Pre-Treatment of Nanoadditives}

Generally the preparation of polymer nanocomposites in systems involving polymers containing inorganic nanofiller is often accompanied by problems related to agglomeration of nanoparticles as well as negative influences on processability, thermal behavior and crystallization of the polymer matrix. These negative factors consequently also appear in the mechanical properties of the prepared polymer nanocomposite. In the search for a way 
to decrease the agglomeration of nano-particles, we have explored the possibility of decreasing the natural polar interactions among the nanoparticles of the additives and so to decrease their agglomeration. Therefore, in this work we investigated pre-treatment procedures for the nanoadditives prior to the preparation of PP/inorganic filler nanocomposite. The pre-treatment procedures involved the combining of nanoadditives with the solvents glycerine or acetone, and subjecting the mixtures to a variety of conditions of mechanical stirring and utrasonication in an effort to improve adsorption of the solvent molecules on the surface of the nano-particles and ultimately achieve a positive influence on the behavior of additive PP matrix.

The additives i.e. $\mathrm{nCaCO}_{3}$ or $\mathrm{C} 30 \mathrm{~B}$ in glycerine $(\mathrm{C} 30 \mathrm{~B})$ or acetone in the ratio 1:5 (solid to liquid) were given pretreatments before mixing with PP. There were used three treatment methods: 1) mechanically mixing of NA particles in glycerine or acetone dispersion, 2) sonicating a beaker of the NA-liquid dispersion in the solvent which had been placed in a water bath of the ultrasonicator (U) and 3) sonicating while simultaneously mechanically mixing the beaker of dispersion of NA in solvent in the water bath of the sonicator (MU). The time of treatment of filler in all cases was 5 minutes. The dispersions were filtered, rinsed by deionized water and ethanol and dried at room temperature.

The literature describes similar ultrasound treatments of nanoparticles of various nanoadditives like nano zinc oxide or $\mathrm{nCaCO}_{3}$ for improvement of their dispersability in polymers or polymer systems, to facilitate the preparation of polymer blends or emulsions $[18,21,22]$.

\subsubsection{Preparation of the PP/NA Masterbatch and Modified PP/NA Fibres}

The fibres modified by nanoadditives $\mathrm{nCaCO}_{3}$ or $\mathrm{C} 30 \mathrm{~B}$ were prepared in two steps:

1) Preparation of masterbatches contained $15 \mathrm{wt} \%$ of $\mathrm{nCaCO}_{3}$ or $\mathrm{C} 30 \mathrm{~B}$ : The isotactic PP was mixed with the appropriate amount of modified nano-additive and meltcompundeded in a twin screw extruder with diameter $\phi=$ $16 \mathrm{~mm}$ at extrusion temperature $493 \mathrm{~K}$. Finally, the extrudate was cooled and pelletized. The resulting pellets of masterbatches containing $15 \mathrm{wt} \%$ of the additive $\left(\mathrm{nCaCO}_{3}\right.$ or $\left.\mathrm{C} 30 \mathrm{~B}\right)$ were used for the preparation of $\mathrm{PP} / \mathrm{NA}$ mixtures with required content of NA additives suitable for spinning.

2) Preparation of $\mathrm{PP} / \mathrm{nCaCO}_{3}$ or $\mathrm{PP} / \mathrm{C} 30 \mathrm{~B}$ fibres. The pellets of $15 \mathrm{wt} \%$ masterbatch (of $\mathrm{nCaCO}_{3}$ or $\mathrm{C} 30 \mathrm{~B}$ ) were mixed mechanically with the appropriate amount of $\mathrm{PP}$ to obtain a mixture containing of $1.5 \mathrm{wt} \% \mathrm{nCaCO}_{3}$ or $\mathrm{C} 30 \mathrm{~B}$ in the fibre. The individual mechanically stirred mixtures were melt compounded and spun into fibres by classical procedure using a laboratory pilot line with a single screw extruder having $\phi=16 \mathrm{~mm}$, and equipped with a nozzle containing 13 holes, at $513 \mathrm{~K}$, with fibre take up speed of $150 \mathrm{~m} \cdot \mathrm{min}^{-1}$. The resultant primary undrawn fibres were subsequently drawn using laboratory drawing equipment at $383 \mathrm{~K}$. The linear density of the drawn multifilaments was $\mathrm{T}_{\mathrm{dt}}=(21-22)$ dtex $\times \mathrm{f13}$.

\subsection{Characterization Methods}

\subsubsection{Thermal Properties of Unmodified and Modified PP Fibres}

The evaluation of thermal behaviour of unmodified PP and modified $\mathrm{PP} / \mathrm{nCaCO}_{3}$ or $\mathrm{PP} / \mathrm{C} 30 \mathrm{~B}$ fibres in the form of heating or cooling programs was performed using a DSC apparatus (Perkin Elmer). The thermal behavior characteristics were estimated for the non-isothermal and isothermal processes.

The following typical procedure is presented for the non-isothermal analysis: A sample of the original fibre was heated at a rate of $10 \mathrm{~K} \cdot \mathrm{min}^{-1}$ from $343 \mathrm{~K}$ to $493 \mathrm{~K}$, then the sample was isothermally held at $493 \mathrm{~K}$ for 5 minutes to remove the thermal history of the fibre preparation. Thus, a melting endotherm of the original sample with a melting temperature $\mathrm{T}_{\mathrm{m}}$ and melting enthalpy $\Delta H_{m}$ was obtained. The sample was then cooled at a rate of $10 \mathrm{~K} \cdot \mathrm{min}^{-1}$ and the crystallisation exotherm with crystallisation temperature $\mathrm{T}_{\mathrm{c}}$ and crystallisation enthalpy $\Delta H_{c}$ were determined. Subsequently, the sample was exposed to a second heating at a rate of $10 \mathrm{~K} \cdot \mathrm{min}^{-1}$ from $343 \mathrm{~K}$ to $473 \mathrm{~K}$ and the endotherm with a melting point $\mathrm{T}_{\mathrm{m}}$, and melting enthalpy $\Delta H_{m}$ was again determined. The actual melting enthalpy $\Delta H_{100}$ is related to enthalpy of weight fraction $w$ of PP

$$
\Delta H_{100}=\frac{\Delta H_{\exp (w)}}{w}
$$

where $w$ is the weight fraction of $\mathrm{PP}$ in the modified $\mathrm{PP} / \mathrm{nCaCO}_{3}$ or $\mathrm{PP} / \mathrm{C} 30 \mathrm{~B}$ samples. All measurements were carried out in nitrogen atmosphere.

The effect of $\mathrm{nCaCO}_{3}$ or $\mathrm{C} 30 \mathrm{~B}$ on the non-isothermal crystallization behavior of $\mathrm{PP}$ in the modified $\mathrm{PP} / \mathrm{nCaCO}_{3}$ or $\mathrm{PP} / \mathrm{C} 30 \mathrm{~B}$ isotropic blends was studied by evaluation of initial crystallization temperature $T_{\text {co }}$, peak temperature of crystallization $T_{c p}$, half height width of crystallization $\Delta \mathrm{W}_{\mathrm{c}}$, temperature difference between $\mathrm{T}_{\mathrm{co}}$ and $\mathrm{T}_{\mathrm{cp}}$ $\left(\Delta \mathrm{T}_{\mathrm{c}}=\mathrm{T}_{\mathrm{co}}-\mathrm{T}_{\mathrm{cp}}\right)[18]$ as well as by estimation of other thermal properties such as $n$ and $K$ from Avrami equation. Crystallization half-time $t_{1 / 2}$, rate of crystallization $\tau_{1 / 2}$, the necessary time for maximum crystallization $t_{\max }$ and free energy per unit area of surface in the lamella perpendicular to the axis of a high-molecular chain $\sigma_{e}$ were also determined. These parameters were estimated using isothermal crystallization and non-isothermal processes at 5 different cooling rates $\left(5,10,20,30\right.$ and $\left.50 \mathrm{~K} \cdot \mathrm{min}^{-1}\right)$. 


\subsubsection{Mechanical Properties of Composite PP Fibres Modified by $\mathrm{nCaCO}_{3}$ or C30B}

The apparatus, Instron 1122, was used for the estimation of the tenacity, Young's modulus as well as elongation of the modified $\mathrm{PP} / \mathrm{nCaCO}_{3}$ or $\mathrm{PP} / \mathrm{C} 30 \mathrm{~B}$ fibres in accordance with standard testing procedures (Standard ISO 2062:1993).

\subsubsection{Barrier Properties of Unmodified and Modified PP Fibres}

A quantitative spectrophotometric test was used for quantitative evaluation of the ultraviolet shielding effect of $\mathrm{nCaCO}_{3}$ or $\mathrm{C} 30 \mathrm{~B}$ modified PP fibres. A spectrophotometer, Libra S12 with deuterium lamp was used for measuring the transmittance through a sample of reeled fibre. Accordingly, the ultraviolet protective factor (UPF) was calculated using the standard specification STN EN 13758-1:2001 for textile materials. In this case, this specification was adapted for fibres [19]:

$$
U P F=\frac{\sum_{290}^{400} E(\lambda) \times \varepsilon(\lambda) \times \Delta(\lambda)}{\sum_{290}^{400} E(\lambda) \times T(\lambda) \times \varepsilon(\lambda) \times \Delta(\lambda)}
$$

where $E(\lambda)$-relative erythermal spectral effectiveness $\left(\mathrm{W} / \mathrm{m}^{2} \cdot \mathrm{nm}\right), \varepsilon(\lambda)$ - solar spectral irradiance (Melbourne), $\mathrm{T}(\lambda)$ - spectral transmittance of the sample $(\%), \Delta \lambda-$ bandwidth $(\mathrm{nm}), \lambda$-wavelength $(\mathrm{nm})$.

\section{Results and Discussion}

\subsection{Thermal Properties of $\mathrm{PP} / \mathrm{nCaCO}_{3}$ and PP/C30B Nanocomposite Fibres}

It is known that nanofillers influence the characteristics of polymer/filler nanocomposite melt (e.g. viscosity), but also the process of formation of supermolecular morphology during the crystallization occurring in the cooling of melt, as well as the end-use properties of prepared fibre materials $[20,23]$. It follows from this, that the spinning process and drawing of the resultant fibres of the systems polypropylene- $\mathrm{PP} / \mathrm{CaCO}_{3}$ or $\mathrm{PP} / \mathrm{C} 30 \mathrm{~B}$ will be affected too. Therefore the modification of PP fibres with special additives like nano-particles of inorganic origin allows for the preparation of new fibre materials with improved properties and with potentially quite new applications [20, 23-25].

Melting behaviour of modified $\mathrm{PP} / \mathrm{nCaCO}_{3}$ and $\mathrm{PP} / \mathrm{C} 30 \mathrm{~B}$ fibres was studied at a heating rate of $10 \mathrm{~K} \cdot \mathrm{min}^{-1}$ (Figures 1 and 2). At the first heating for the anisotropic as well as at the second heating for the isotropic $\mathrm{PP} / \mathrm{nCaCO}_{3}$ and $\mathrm{PP} / \mathrm{C} 30 \mathrm{~B}$ fibres containing various pre-treated nanoadditives, the peaks with the melting temperatures from 434,3 to 438,5 K were determined (Figures 1, 2;
Table 1). These temperatures correspond to the melting temperature of the $\alpha$-modification of PP. The type and manner of pre-treatment of nanoadditives differently affect the formation of super-molecular structure, which is characterized by the various peak shapes on the DSC

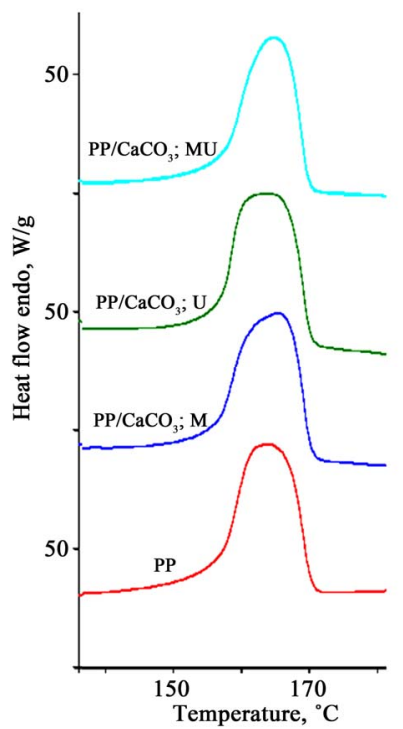

(a)

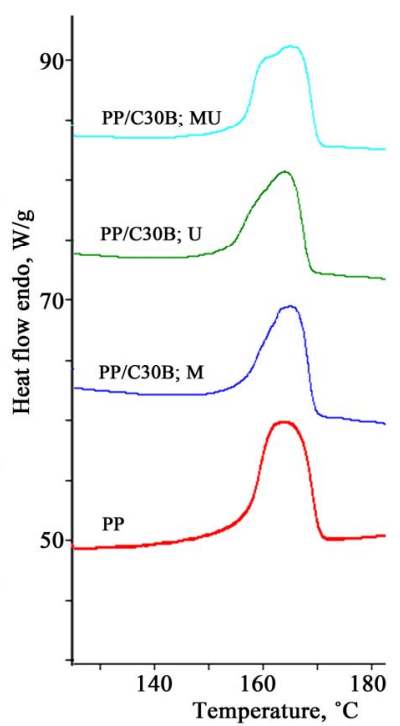

(b)
Figure 1. Nonisothermal endotherms of PP and composite PP fibres containing $\mathrm{nCaCO}_{3}$ (a) and $\mathrm{C30B}$ (b) with the various pre-treatment of nanoadditives obtained at the heating rate of $10 \mathrm{~K} \cdot \mathrm{min}^{-1}$ for the $1^{\text {st }}$ heating $(\mathrm{M}-$ mechanical mixing, $\mathrm{U}$ - ultrasound, MU-simultaneously mechanical mixing and ultrasound).

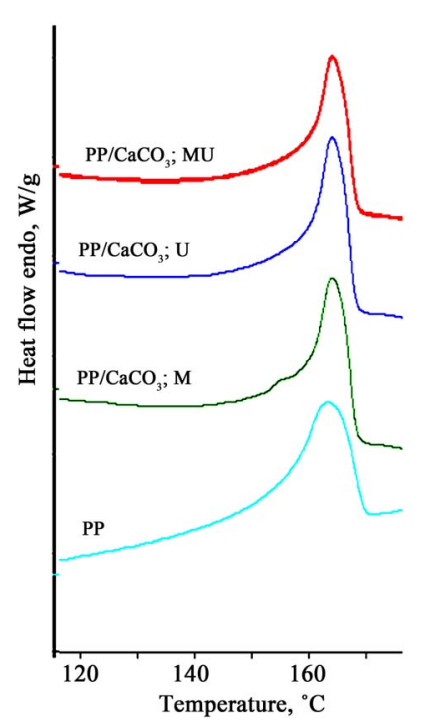

(a)

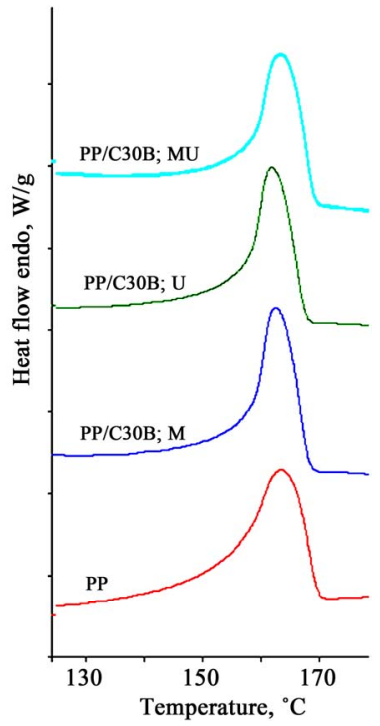

(b)
Figure 2. Nonisothermal endotherms of $P P$ and composite $\mathrm{PP}$ fibres comtaining $\mathrm{nCaCO}_{3}$ (a) and $\mathrm{C30B}$ (b) with the various pre-treatment of nanoadditives obtained at the heating rate of $10 \mathrm{~K} \cdot \mathrm{min}^{-1}$ for the $2^{\text {nd }}$ heating $(\mathrm{M}-$ mechanical mixing, U-ultrasound, MU-simultaneously mechanical mixing and ultrasound). 
thermograms. The first heating of anisotropic $\mathrm{PP} / \mathrm{nCaCO}_{3}$ fibres containing $\mathrm{nCaCO}_{3}$ produced DSC thermograms with wide and flat peaks. PP containing anisotropic $\mathrm{PP} / \mathrm{C} 30 \mathrm{~B}-$ based fibres crystallized in the modified morphological structure characterized by narrow and sharp peaks on the thermograms. The peak at the endotherm reflects the thermal history of fibre preparation and indicates PP crystallization during the spinning and drawing of the fibres in the presence nanoadditives. During the second heating, isotropic $\mathrm{PP} / \mathrm{nCaCO}_{3}$ and $\mathrm{PP} / \mathrm{C} 30 \mathrm{~B}$ systems show endotherms with narrow peaks for both nanoadditives (Figure 2, Table 1). The melting temperatures of the PP crystallites in the $\mathrm{PP} / \mathrm{nCaCO}_{3}$ composite are higher than the melting temperatures of PP in $\mathrm{PP} / \mathrm{C} 30 \mathrm{~B}$ systems. This can be attributed to the chemical modification of $\mathrm{C} 30 \mathrm{~B}$ particles with organic quartery alkylammonium salt by the commercial producer. The purpose of the quaternary salt additives is for the improvement of affinity to the hydrophobic chains of the polypropylene which can restrain formation of PP crystallized phase. In the case of $\mathrm{nCaCO}_{3}$ particles which were not chemically modified, one observes the formation of PP crystallites with larger sizes.

Another observation was noted during the crystallization of these materials after holding them isothermally for $5 \mathrm{~min}$ at $493 \mathrm{~K}$ (Figure 3, Table 1). The PP melt containing $\mathrm{nCaCO}_{3}$ starts to crystallize at a higher temperature than in the blend containing $\mathrm{C} 30 \mathrm{~B}$ or in the pure PP. All three methods of the pre-treatment of nanoadditives incorporated into the PP matrix did not show any differences in crystallization temperatures. However, the rate of PP crystallization in the fibres containing $\mathrm{nCaCO}_{3}$ is higher than for $\mathrm{C} 30 \mathrm{~B}$ at the same cooling rate, which demonstrates the decrease of $\Delta \mathrm{T}_{\mathrm{c}}$ or $\Delta \mathrm{W}_{\mathrm{c}}$, mainly in the case of the $\mathrm{nCaCO}_{3}$ - based composite [17]. This means that at these conditions, the $\mathrm{C} 30 \mathrm{~B}$ does not behave like a nucleating agent. Only the use of mechanical mixing or ultrasound on $\mathrm{C} 30 \mathrm{~B}$ is the nucleation effect increased, but not at the level of the $\mathrm{nCaCO}_{3}$ system (Table 1).

These results show that the presence of additives in the $\mathrm{PP}$ fibres, i.e. $\mathrm{PP} / \mathrm{nCaCO}_{3}$ and to a lesser extent $\mathrm{PP} / \mathrm{C} 30 \mathrm{~B}$, produced increased melting and/or crystallization enthalpies, mainly at the first heating. This became most evident with the pre-treatment using ultrasound and also with simultaneous mechanical mixing with ultrasound (US) (Table 2). But in the presence of $\mathrm{C} 30 \mathrm{~B}$, very little decrease of $\Delta \mathrm{T}_{\mathrm{c}}$ and $\Delta \mathrm{W}_{\mathrm{c}}$ were obtained. This is related to the inability of $\mathrm{C} 30 \mathrm{~B}$ to promote nucleation of crystallization in PP. This observation indicates that pre-treatment of nanoparticles of both types of nanofillers $\left(\mathrm{nCaCO}_{3}\right.$ and $\mathrm{C} 30 \mathrm{~B}$ ) contributes some influence on the thermal behavior of PP nanocomposite fibres.

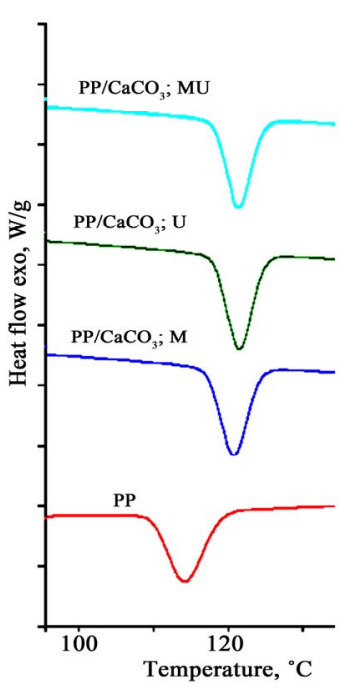

(a)

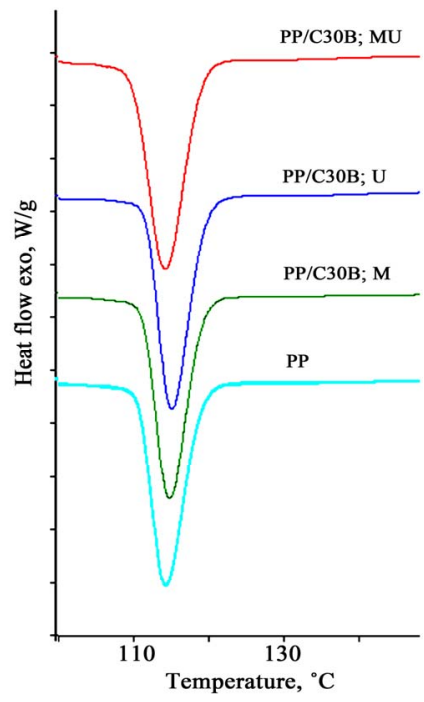

(b)
Figure 3. Nonisothermal enxotherms of $P P$ and composite $\mathrm{PP}$ fibres containing $\mathrm{nCaCO}_{3}$ (a) and $\mathrm{C30B}$ (b) with the various pre-treatment of nanoadditives obtained at the cooling rate of $10 \mathrm{~K} \cdot \mathrm{min}^{-1}(\mathrm{M}-$ mechanical mixing, $\mathrm{U}$ ultrasound, MU-simultaneously mechanical mixing and ultrasound).

Table 1. Melting temperatures obtained during $1^{\text {st }}\left(T_{m 1}\right)$ and $2^{\text {nd }}\left(T_{m 2}\right)$ heating and crystallization temperature (onset $T_{\text {co }}$, peak $\left.T_{c p}\right), \Delta T=T_{c o}-T_{c p}$, half height width of crystallization $(\Delta W)$ of PP, PP/nCaCO $\mathrm{Can}_{3}$ aP/C30B fibres (M-mechanical mixture, $\mathrm{U}$ - ultrasound, UM-both simultaneously).

\begin{tabular}{|c|c|c|c|c|c|c|c|}
\hline $\begin{array}{l}\text { Type and content of nanoadditives in } \\
\text { PP fibres }\end{array}$ & Treatment of nanoadditives & $\begin{array}{c}\mathbf{T}_{\mathbf{m} 1} \\
\mathbf{K}\end{array}$ & $\begin{array}{c}\mathbf{T}_{\mathbf{m} 2} \\
\mathbf{K}\end{array}$ & $\begin{array}{c}\mathbf{T}_{\mathrm{co}} \\
\mathbf{K}\end{array}$ & $\begin{array}{c}\mathbf{T}_{\mathrm{cp}} \\
\mathbf{K}\end{array}$ & $\underset{\mathbf{K}}{\Delta \mathbf{T}}$ & $\begin{array}{c}\Delta \mathbf{W} \\
\mathbf{K}\end{array}$ \\
\hline \multirow[t]{2}{*}{ PP fibres $(0.0 \mathrm{wt} \%)$} & - & 436.0 & 435.9 & 391,8 & 387.2 & 4.6 & 5.0 \\
\hline & M & 438.5 & 437.2 & 397.3 & 393.8 & 3.5 & 3.9 \\
\hline \multirow[t]{3}{*}{$\mathrm{nCaCO}_{3}(3.0 . \mathrm{wt} \%)$} & $\mathrm{U}$ & 437.0 & 437.0 & 397.9 & 394.5 & 3.4 & 3.8 \\
\hline & UM & 437.7 & 437.2 & 397.7 & 394.3 & 3.4 & 3.7 \\
\hline & M & 438.3 & 435.5 & 392.5 & 388.1 & 4.3 & 4.5 \\
\hline \multirow[t]{2}{*}{ C30B (3.0. wt \%) } & $\mathrm{U}$ & 437.0 & 434.7 & 392.1 & 387.8 & 4.3 & 4.5 \\
\hline & UM & 438.3 & 436.4 & 391.9 & 387.3 & 4.6 & 4.9 \\
\hline
\end{tabular}


Melting and crystallization enthalpies of PP in the $\mathrm{PP} / \mathrm{C} 30 \mathrm{~B}$ anisotropic or isotropic systems are lower than for pure PP. The highest effect on the PP crystallization from the standpoint of pre-treatment of nanoadditives before their incorporation into the polymer/fibres has been achieved by using mechanical mixing with simultaneous application of ultrasound (Table 2). This method probably promotes improved dispersion of the nanoadditive particles.

As it is generally known, the crystallization process of polymers such as PP is complex and depends on temperature. The relative degree of crystallinity increases with an increase in crystallization time $t$, as is described by the Avrami equation [26,27]:

$$
X_{c}=1-e^{-K \cdot t^{n}}
$$

The parameters $n$ and $K$ determined from double logarithmic plots (Figures 4 and 5) are shown in Table 3. The Avrami parameter $n$ is in the range from 2.6 to 4.8 , depending on type or pre-treatment of nanoadditives
$\left(\mathrm{nCaCO}_{3}, \mathrm{C} 30 \mathrm{~B}\right)$. These values indicate heterogeneous nucleation with the creation of two- and three-dimensional diffusion-controlled growth of spherulites. All pretreatment methods applied to $\mathrm{nCaCO}_{3}$ additives indicated mainly two-dimensional growth. The various kinds of pre-treatments for C30B additives support a different nucleation mechanism for PP. Small variations of the Avrami index $n$ can result from experimental and specific errors of the Avrami model [26], as well as by the existence of both primary and secondary crystallization in the material [28]. Also, the kinetics of PP crystallization is influenced by the type of pretreatment applied to the nanoadditives (Table 3). The most rapid PP crystallization was observed in the presence of $\mathrm{nCaCO}_{3}$ pretreated by ultrasound (the highest of $K, \tau_{1 / 2}$ and lowest $t_{1 / 2}$, $\left.t_{\max }\right)$. The end surface free energy needed for the creation of new crystalline surfaces in the crystallites during this heterogeneous nucleation is lowest, as well. The values of $K, \tau_{1 / 2}$ and lowest $t_{1 / 2}, t_{\max }$ confirm the lower PP crystallization rate in the presence of $\mathrm{C} 30 \mathrm{~B}$ in comparison with $\mathrm{nCaCO}_{3}$ (Table 3).

Table 2. Melting (experimental- $\Delta H_{m}$ and calculated- $\left.\Delta H_{m c a l c}\right)$ and crystallization $\left(\Delta H_{c}\right)$ enthalpies for the $1^{\text {st }}(1)$ and $2^{\text {nd }}(2)$ heating and crystallization of $\mathrm{PP}, \mathrm{PP} / \mathrm{nCaCO}_{3}$ and $\mathrm{PP} / \mathrm{C30B}$ fibres $(\mathrm{M}-$ mechanical mixture, $\mathrm{U}-\mathrm{ultrasound}$, UM-both simultaneously).

\begin{tabular}{|c|c|c|c|c|c|c|}
\hline $\begin{array}{l}\text { Type and content of nanoadditives in } \\
\text { PP fibres }\end{array}$ & Treatment of nanoadditives & $\begin{array}{l}\Delta H_{m 1} \\
\mathbf{J} \cdot \mathbf{g}^{-1}\end{array}$ & $\underset{\mathbf{J} \cdot \mathbf{g}^{-1}}{\Delta \boldsymbol{H}_{\mathbf{1}} \text { calc }}$ & $\begin{array}{c}\Delta H_{c} \\
\mathbf{J} \cdot \mathbf{g}^{-1}\end{array}$ & $\underset{\mathbf{J} \cdot \mathbf{g}^{-1}}{\Delta H^{2}}$ & $\underset{\mathbf{J} \cdot \mathbf{g}^{-1}}{\Delta \boldsymbol{H}_{m 2 \text { alc }}}$ \\
\hline \multirow[t]{2}{*}{ PP fibres $0.0 \mathrm{wt} \%$} & - & 99.3 & 99.3 & 113.5 & 100.9 & 100.9 \\
\hline & M & 99.6 & 102.7 & 110.8 & 103.5 & 106.7 \\
\hline \multirow[t]{3}{*}{$\mathrm{nCaCO}_{3} 3.0 . \mathrm{wt} \%$} & $\mathrm{U}$ & 100.8 & 104 & 112.7 & 106.6 & 109.9 \\
\hline & UM & 100.6 & 103.8 & 109.8 & 96.5 & 99.5 \\
\hline & M & 85.4 & 88.0 & 100.3 & 88.4 & 91.1 \\
\hline \multirow[t]{2}{*}{ C30B 3.0. wt $\%$} & $\mathrm{U}$ & 88.1 & 90.8 & 102.5 & 89.6 & 92.4 \\
\hline & UM & 92.0 & 94.8 & 105.1 & 81.4 & 94.2 \\
\hline
\end{tabular}

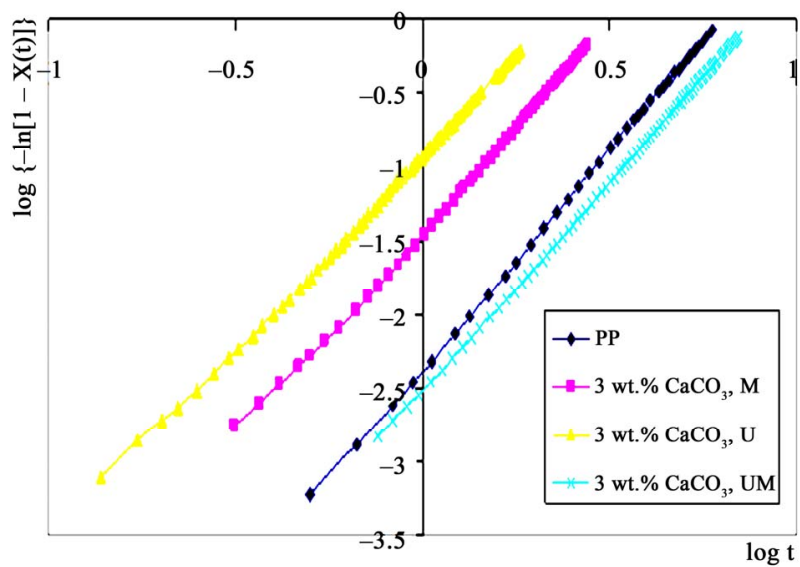

Figure 4. Plots of $\log \{-\ln [1-X(t)]\}$ versus $\log t$ for isothermal crystallization at $403 \mathrm{~K}$ of $\mathrm{PP} / \mathrm{nCaCO}_{3}$ fibre with content of $3 \mathrm{wt} \% \mathrm{nCaCO}_{3}$ with various pre-treatment methods.

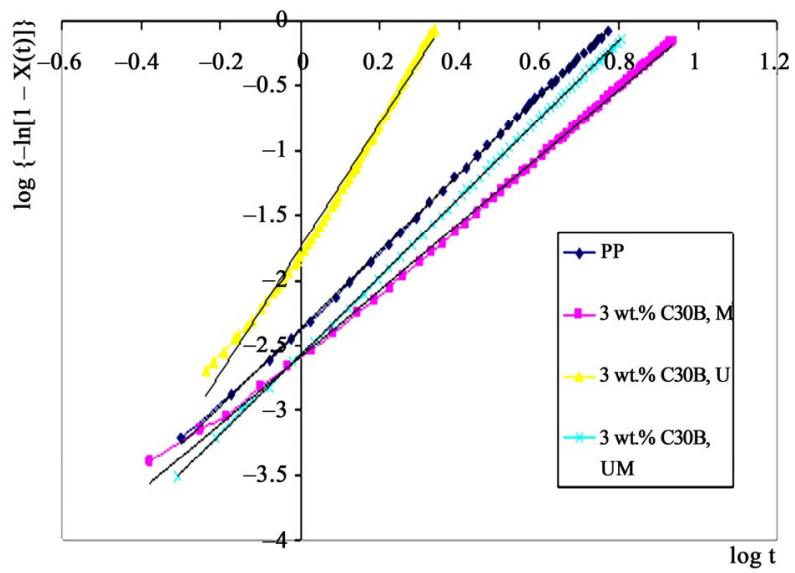

Figure 5. Plots of $\log \{-\ln [1-X(t)]\}$ versus $\log t$ for isothermal crystallization at $403 \mathrm{KC}$ of $\mathrm{PP} / \mathrm{C30B}$ fibre with content of $3 \mathrm{wt} \% \mathrm{C} 30 \mathrm{~B}$ using various pre-treatment methods. 


\subsection{Mechanical Properties of $\mathrm{PP} / \mathrm{nCaCO}_{3}$ and PP/C30B Nanocomposite Fibres}

Generally, any amount of solid particles (micro- or nano-) incorporated into a polymer, decreases the orientation of an anisotropic system of fibres or films. The solid particles impede drawingability of fibre-forming polymers during their production. The lower drawingability of PP decreases the orientation of the PP matrix of the fibres as well as their mechanical properties (Table 4). The data show that the mechanical properties (mainly tenacity and elongation at the break) of $\mathrm{PP} / \mathrm{nCaCO}_{3}$ and $\mathrm{PP} / \mathrm{C} 30 \mathrm{~B}$ fibres are lower than for neat PP fibres.

The lowest decrease of tenacity was observed with the $\mathrm{PP} / \mathrm{nCaCO}_{3}$ fibres, where the additive $\mathrm{nCaCO}_{3}$ was pretreated simultaneously by mechanical mixing and ultrasound. This agrees with the slowest rate of PP crystallization in $\mathrm{PP} / \mathrm{nCaCO}_{3}$ fibres (Tables 3 and 4). Similar results were obtained with the $\mathrm{PP} / \mathrm{C} 30 \mathrm{~B}$ fibres pre-treated by mechanical mixing and ultrasound, where a decrease of tenacity and Young's modulus were observed. The total decrease in mechanical properties of $\mathrm{PP} / \mathrm{C} 30 \mathrm{~B}$ fibres is greater than PP containing $\mathrm{nCaCO}_{3}$. Some decrease of mechanical properties of $\mathrm{PP} / \mathrm{nCaCO}_{3}$ and $\mathrm{PP} / \mathrm{C} 30 \mathrm{~B}$ fibres was expected because the nanocomposite
PP fibres were prepared without any compatibilizers, as is usually used $[29,30]$. But the limited decrease of mechanical properties does not exclude the possibility for their practical use.

\subsection{Barrier Properties against UV Radiation of $\mathrm{PP} / \mathrm{nCaCO}_{3}$ and PP/C30B Nanocomposite Fibres}

The $\mathrm{PP} / \mathrm{nCaCO}_{3}$ and $\mathrm{PP} / \mathrm{C} 30 \mathrm{~B}$ fibres were tested for the UPF parameter, which characterizes the ability of textile materials to protect human skin against UV radiation (Table 4). Because the nanoparticles of these additives improve the shielding properties of fibres by light beam reflection at their edges, it is expected that reduced penetration of harmful UV irradiation through the fibre can find practical use in certain environments. With simultaneous pre-treatment by mechanical mixing and ultrasonication, the $\mathrm{nCaCO}_{3}$ nanoadditive could be converted into an effective dispersion of nanoparticles before their incorporation into the fibres. With higher content of $\mathrm{nCaCO}_{3}$, the UV radiation beam reflection increased and so proportionally, also did the UV protection parameter. The more significant UV protection (higher UPF parameter) of PP fibres was observed with the $\mathrm{PP} / \mathrm{nCaCO}_{3}$ fibres in comparison to $\mathrm{PP} / \mathrm{C} 30 \mathrm{~B}$ fibres.

Table 3. Avrami parameters $n, K, t_{1 / 2}, t_{\mathrm{max}}, \tau_{1 / 2}$ and end surface free energies $\left(\sigma_{\varepsilon}\right)$ of $\mathrm{PP}, \mathrm{PP} / \mathrm{nCaCO}$ and $\mathrm{PP} / \mathrm{C} 30 \mathrm{~B}$ fibres (M-mechanical mixture, $\mathrm{U}$ - ultrasound, $\mathrm{UM}$ - both simultaneously).

\begin{tabular}{|c|c|c|c|c|c|c|c|}
\hline $\begin{array}{l}\text { Type and content of nanoadditives in } \\
\text { PP fibres }\end{array}$ & Treatment of nanoadditives & $n$ & $\begin{array}{l}K \cdot 10^{3} \\
\min ^{-1}\end{array}$ & $\begin{array}{c}t_{1 / 2} \\
\min \end{array}$ & $\begin{array}{l}t_{\max } \\
\min \end{array}$ & $\begin{array}{c}\tau_{1 / 2} \\
\min \end{array}$ & $\begin{array}{c}\sigma_{e} \cdot 10^{-1} \\
\mathbf{J} \cdot \mathbf{m}^{-2}\end{array}$ \\
\hline \multirow[t]{2}{*}{ PP fibres $0.0 \mathrm{wt} \%$} & - & 2.99 & 4.2 & 5.48 & 5.41 & 0.18 & 23.4 \\
\hline & M & 2.81 & 36.2 & 2.87 & 2.79 & 0.35 & 21.8 \\
\hline \multirow[t]{3}{*}{$\mathrm{nCaCO}_{3} 3.0 . \mathrm{wt} \%$} & $\mathrm{U}$ & 2.65 & 119.2 & 1.91 & 1.85 & 0.52 & 20.3 \\
\hline & $\mathrm{UM}$ & 2.84 & 2.9 & 7.00 & 6.82 & 0.14 & 25.0 \\
\hline & M & 2.57 & 2.6 & 8.57 & 8.19 & 0.12 & 25.8 \\
\hline \multirow[t]{2}{*}{ C30B 3.0. wt $\%$} & $\mathrm{U}$ & 4.82 & 17.9 & 2.14 & 2.20 & 0.47 & 14.4 \\
\hline & $\mathrm{UM}$ & 3.03 & 2.6 & 6.44 & 6.35 & 0.16 & 21.8 \\
\hline
\end{tabular}

Table 4. Tenacity $(\sigma)$ and elongation $(\varepsilon)$ at the break, Young's modulus $(E)$ and Ultraviolet protective factor (UPF) of PP, $\mathrm{PP} / \mathrm{nCaCO}_{3}$ and $\mathrm{PP} / \mathrm{C30B}$ fibres (M-mechanical mixture, $\mathrm{U}$ - ultrasound, $\mathrm{UM}$ - both simultaneously).

\begin{tabular}{|c|c|c|c|c|c|}
\hline $\begin{array}{l}\text { Type and content of nanoadditives in } \\
\text { PP fibres }\end{array}$ & Treatment of nanoadditives & $\begin{array}{c}\sigma \\
\mathbf{c N} \cdot \operatorname{tex}^{-1}\end{array}$ & $\begin{array}{c}E \\
N \cdot \operatorname{tex}^{-1}\end{array}$ & $\begin{array}{r}\varepsilon \\
\%\end{array}$ & UPF \\
\hline \multirow[t]{2}{*}{ PP fibres $0.0 \mathrm{wt} \%$} & - & 24.3 & 2.00 & 163.2 & 9.25 \\
\hline & M & 16.5 & 2.00 & 113.3 & 10.10 \\
\hline \multirow[t]{3}{*}{$\mathrm{nCaCO}_{3}$ 3.0. wt $\%$} & $\mathrm{U}$ & 16.8 & 1.76 & 75.4 & 14.47 \\
\hline & UM & 20.1 & 2.00 & 101.5 & 17.98; \\
\hline & M & 10.5 & 1.20 & 165.2 & 13.91 \\
\hline \multirow[t]{2}{*}{$\mathrm{C} 30 \mathrm{~B} 3.0 . \mathrm{wt} \%$} & $\mathrm{U}$ & 12.0 & 1.30 & 31.4 & 8.99 \\
\hline & UM & 12.9 & 1.80 & 55.3 & 12.58 \\
\hline
\end{tabular}




\section{Conclusions}

- The melting temperatures for first and second heating of PP modified by $\mathrm{C} 30 \mathrm{~B}$ and $\mathrm{nCaCO}_{3}$ and treated by various methods are the same as the melting temperature of pure PP fibre.

- The $\mathrm{nCaCO}_{3}$ or $\mathrm{C} 30 \mathrm{~B}$ fillers pre-treated by all three methods influenced the increase of the PP crystallization temperatures in comparison with the pure PP fibres.

- The pre-treatment methods used on the nanoadditives influenced an increase of $n, K, \tau_{1 / 2}$ values and a decrease of $t_{1 / 2}, t_{\max }$ as well as the values of free surface energies per unit area of PP fibres modified with $\mathrm{C} 30 \mathrm{~B}$ and $\mathrm{nCaCO}_{3}$.

- The use of nanofiller i.e. $\mathrm{nCaCO}_{3}, \mathrm{C} 30 \mathrm{~B}$ in the fibres produced some decrease of mechanical properties of the prepared PP fibres in comparison with neat PP fibres but the decreases do not exclude the fibres from commercial use.

- Use of both, ultrasound or simultaneously mixing with ultrasound as pretreatments of the fillers gave the highest radiation barrier properties i.e. UPF in the fibres.

\section{Acknowledgements}

The research was performed within the task of research of VEGA 1/0444/09 and APVT No. 20-011404.

\section{REFERENCES}

[1] P. H. Nam, P. Maiti, M. Okamoto, T. Kotaka, N. Hasegawa and A. Usuki, "A Hierarchical Structure and Properties of Intercalated Polypropylene/Clay Nanocomposite," Polymer, Vol. 42, No. 23, 2001, pp. 9633-9640.

[2] M. Okamoto, S. Morita and T. Kotaka, "Dispersed Structure and Ionic Conductivity of Smectic Clay/Polymer Nanocomposites," Polymer, Vol. 42, No. 6, 2001, pp. 26852688.

[3] G. Z. Papageorgiou, D. S. Achilias, D. N. Bikiaris and G. P. Karayannidis, "Crystallization Kinetics and Nucleation Activity of Filler in Polypropylene/Surface-Treated $\mathrm{SiO}_{2}$ Nanocomposites," Thermochimica Acta, Vol. 427, No. 12, 2005, pp. 117-128.

[4] M. Joshi and B. S. Butola, "Studies on Nonisothermal Crystallization of HDPE/POSS Nanocomposites," Polymer, Vol. 45, No. 14, 2004, pp. 4953-4968.

[5] A. Chatterjee and B. L. Deopura, "Crystallization Behavior of PP and Carbon Nanofibre Blends," Fibers and Polymers, Vol. 4, No. 3, 2003, pp. 102-106.

[6] J. Ebenhoch, "Zäh Und Hitzebeständing: Neue Silikonpartikel Für Duroplaste," Kunststoffe, Vol. 94, No. 12, 2004, pp. 162-165.

[7] F. Rault, E. Pleyber, C. Campagne, M. Rochery, S. Giraud, S. Bourbigot and E. Devaux, "Effect of Manganese Nanoparticles on the Mechanical, Thermal and Fire
Properties of Polypropylene Multifilament Yarn," Polymer Degradation and Stability, Vol. 94, No. 6, 2009, pp. 955-964.

[8] Q. Yuan, S. Awate and R. D. K. Misra, "Nonisothermal Crystallization Behavior of Polypropylene-Clay Nanocomposites," European Polymer Journal, Vol. 42, No. 9, 2006, pp. 1994-2003.

[9] A. Al-Mulla, J. Mathew, S. K. Yeh and R. Gupta, "Nonisothermal Crystallization Kinetics of PBT Nanocomposites," Composites Part A: Applied Science and Manufacturing, Vol. 39, No. 2, 2008, pp. 204-217.

[10] R. Philips and J. A. E. Manson, "Prediction and Analysis of Nonisothermal Crystallization of Polymers," Journal of Polymer Science Part B: Polymer Physics, Vol. 35, No. 6, 1997, pp. 875-888.

[11] Mc. Di Lorenzo and C. Silvestre, "Non-Isothermal Crystallization of Polymers," Progress in Polymer Science, Vol. 24, No. 6, 1999, pp. 917-950.

[12] F. Perrin-Sarazin, M. T. Ton-That, M. N. Bureau and J. Denault, "Micro- and Nano-Structure in Polypropylene/Clay Nanocomposites," Polymer, Vol. 46, No. 25, 2005, pp. 11624-11634.

[13] A. K. Sarkar, "Textiles for UV Protection," In: R. A. Scott, Eds., Textiles for Protection, Woodhead Publishing Ltd., Sawston, 2005, pp. 355-377.

[14] A. K. Sarkar, "An Evaluation of UV Protection Imparted by Cotton Fabrics Dyed with Natural Colorants," BMC Dermatology, Vol. 4, No. 1, 2004, p. 15.

[15] D. Hanke, P. Altmeyer, B. Böhringer, G. Schindler, U. Schön and M. L. Klotz, "UV Protection by Textiles," Chemical Fibers International, Vol. 47, No. 4, 1997, pp. 130-131.

[16] A. L. N. Da Silva, M. C. G. Rocha, M. A. R. Moraes, C. A. R. Valente and F. M. B. Coutinho, "Mechanical and Rheological Properties of Composites based on Polyolefin and Mineral Additives," Polymer Testing, Vol. 21, No. 1, 2002, pp. 57-60.

[17] P. McGenity, J. Hooper, C. Payhter, A. Riley, C. Nutbeem, N. Elton and J. Adams, "Nucleation and Crystallization of PP by Mineral Fillers: Relationship to Impact Strength," Polymer, Vol. 33, No. 24, 1992, pp. 52155224.

[18] B. Shentu, J. Li and Z. Weng, "Effect of Oleic AcidModified Nano- $\mathrm{CaCO}_{3}$ on the Crystallization Behaviour and Mechanical Properties of Polypropylene," Chinese Journal of Chemical Engineering, Vol. 14, No. 6, 2006, pp. 814-818.

[19] A. Ujhelyiová, M. Dulíková, E. Borsig, P. Alexy, O. Brejka and A. Marcinčin, "Measurement Modification of Barrier Properties against UV Irradiation of PP Composite Fibres," International Polymer Processing, Vol. 27, No. 1, 2012, pp. 98-104.

[20] A. Marcinčin, E. Kormendy, M. Hricová, A. Rusnák and A. P. Aneja, "Rheological Behavior of Polyester Blend and Mechanical Properties of the Polypropylene-Polyester Blend Fibers," Journal of Applied Polymer Science, Vol. 102, No. 5, 2006, pp. $4222-4227$.

[21] Z. G. Cui, K. Z. Shi, Y. Z. Cui and B. P. Binks, "Double 
Phase Inversion of Emulsion Stabilized by a Mixture of $\mathrm{CaCO}_{3}$ Nanoparticles and Sodium Dodecyl Sulphate," Colloids and Surfaces A: Physicochemical and Engineering Aspects, Vol. 329, No. 1-2, 2008, pp. 67-74.

[22] J. G. Tang, Y. Wang, H. Liu and L. A. Belfiore, "Effects of Organic Nucleating Agents and Zinc Oxide Nanoparticles on Isotactic Polypropylene Crystallization," Polymer, Vol. 45, No. 7, 2004, pp. 2081-2091.

[23] M. Krištofič, Z. Náčiniaková, J. Legéň and J. Ryba, "Polypropylene Fibres Modified by Copolyamides Part 1. Preparation of Modifed Fibres and Their Properties," Vlákna a Textil, Vol. 12, No. 3, 2005, pp. 104-110.

[24] M. Dulíková, Z. Strecká, A. Ujhelyiová, J. Legéň and P. Bugaj, "Shielding Effect of Nanoadditives against UV Radiation in Polypropylene Fibres," Fibres and Textiles in Eastern Europe, Vol. 18, No. 5, 2010, pp. 55-58.

[25] A. Marcinčin, M. Hricová, E. Kormendyová, A. Ujhelyiová, J. Broda and J. Janicki, "Polypropylene/(Polyethylene Terephthalate/Polybuthylene Terephthalate) Blend Fibres: Phase Structure and Mechanical Properties," Fibres and Textiles in Eastern Europe, Vol. 14, No. 5, 2006, pp. 92-97.
[26] M. J. Avrami, "Kinetics of Phase Change. II Transformation-Time Relations for Random Distribution of Nuclei," Journal of Chemical Physics, Vol. 8, No. 2, 1940, pp. 212-224.

[27] L., Siyang, Y. Yingning, C. Yi, Z. Hongfang and M. Zhishen, "Isothermal and Nonisothermal Crystallization Kinetics of Nylon-11," Journal of Applied Polymer Science, Vol. 70, No. 12, 1998, pp. 2371-2380.

[28] E. Martuscelli, M. Pracella and L. Crispino, "Crystallization Behaviour of Fractions of Isotactic Polypropylene with Different Degrees of Stereoregularity," Polymer, Vol. 24, No. 6, 1983, pp. 693-699.

[29] Z. Strecká, A. Ujhelyiová, E. Bolhová, P. Alexy and E. Borsig, "Polypropylene Fibers Modified by Polyvinyl Alcohol and Montmorillonite," Journal of the Textile Institute, Vol. 10, No. 4, 2010, pp. 315-323.

[30] E. Borsig, A. Augustínová, A. Ujhelyiová and A. Marcinčin, "The Behavior of the Inorganic Nanofiller in Polypropylene Fibres," Proceedings of the European Polymer Congress 2011, Granada, 26 June-1 July 2011, p. 314. 